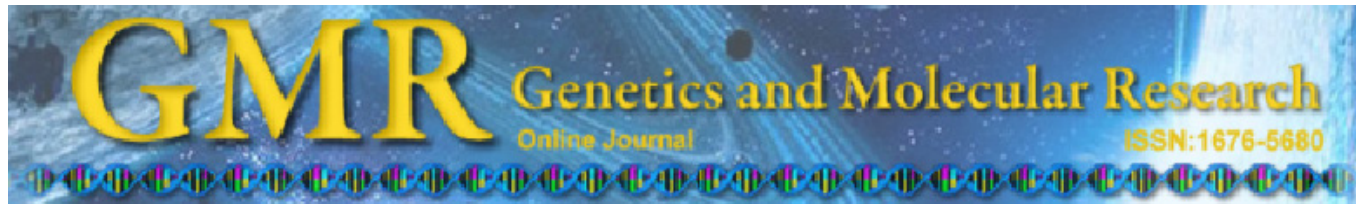

$\underline{\text { Correction }}$

Genet. Mol. Res. 10 (3): 2245-2256 (2011)

DOI http://dx.doi.org/10.4238/vol10-3gmr1197

\title{
Isolation and characterization of 16 novel microsatellite loci in two inbred strains of the Chinese hamster (Cricetulus griseus)
}

\author{
G.-H. Song ${ }^{1,2 *}$, J.-N. Geng ${ }^{3 *}$, R.-Y. Jia ${ }^{3 *}$, W.-B. Yue ${ }^{2}$, T.-F. Liu ${ }^{1}$ and S.-N. Hu ${ }^{3}$ \\ ${ }^{1}$ Laboratory Animal Center, Shanxi Medical University, Taiyuan, China \\ ${ }^{2}$ College of Animal Science and Technology, Shanxi Agricultural University, \\ Taigu, China \\ ${ }^{3}$ Key Laboratory of Genome Information and Sciences, \\ Beijing Institute of Genomics, Chinese Academy of Sciences, Beijing, China
}

The correct institutions of W.-B. Yue and T.-F. Liu are printed above.

The correct institution of W.-B. Yue is College of Animal Science and Technology, Shanxi Agricultural University, Taigu, China.

The correct institution of T.-F. Liu is Laboratory Animal Center,

Shanxi Medical University, Taiyuan, China.

Genet. Mol. Res. 11 (4): 3846 (2012)

Published November 9, 2012

DOI http://dx.doi.org/10.4238/2012.November.9.1 